\title{
LA POLÍTICA ECONÓMICA FRENTE A LA CRISIS ECONÓ- MICA ESTÁ SIENDO INSUFICIENTE PARA RETOMAR EL CRECIMIENTO
}

THE ECONOMIC POLICY FACING THE ECONOMIC CRISIS IS BEING INSUFFICIENT TO RESUME GROWTH

Arturo huerta GonzÁlez'

\begin{abstract}
Resumen: El trabajo analiza cómo la crisis económica que se enfrenta a raíz del Covid-19, los gobiernos y los bancos centrales de los países desarrollados están incrementando el gasto público y bajando la tasa de interés a niveles cercanos a cero y aún así no logran superar los problemas. Los países menos desarrollados se ven limitados para flexibilizar su política fiscal y monetaria, lo que junto con la falta de cooperación internacional, hace que la pandemia y la crisis se acentúen. La pandemia llega a México cuando la economía ya enfrentaba una recesión, lo que la coloca en debilidad para encarar los problemas. El gobierno mexicano, en lugar de cambiar la política de austeridad fiscal causante del estancamiento, la mantiene, por lo que se ahondan los problemas, evidenciando que no está dimensionando la magnitud de la crisis. No hay perspectivas de que las exportaciones, remesas, turismo, entrada de capitales, vuelvan a crecer como antes de la crisis, por lo que al no cambiar la política monetaria y fiscal, la crisis será prolongada. El artículo propone replantear nuestra inserción en la globalización, sí como políticas económicas para el combate a la pandemia y para alcanzar un crecimiento sostenido con pleno empleo.
\end{abstract}

${ }^{1}$ El presente trabajo se inscribe en el Proyecto de Investigación del PAPIIT de la UNAM, IN305419, "Libre Comercio vs proteccionismo: sus consecuencias sobre el crecimiento y las variables macroeconómicas".

Profesor del Posgrado, Facultad de Economía, UNAM. Contacto: <ahuerta@unam. mx>. ORGID: https://orcid.org/0000-0002-0986-6404. Fecha de recepción: 7 de junio de 2020; fecha de aprobación: 15 de septiembre de 2020. 
Palabras Glave: Pandemia, Grisis, déficit fiscal, austeridad fiscal, expansión monetaria.

Abstract: The work analyzes how the economic crisis faced by Covid-19, the governments and central banks of developed countries are increasing public spending and lowering the interest rate to levels close to zero and yet they still cannot exceed the problems. The least developed countries are limited in making their fiscal and monetary policies more flexible to recover the economic growth, which together with the lack of international cooperation, makes the pandemic and the crisis worse. The pandemic arrives in Mexico when the economy was already facing a recession, which leaves it weak to face the problems. The Mexican government, instead of changing the policy of fiscal austerity that caused the stagnation, maintains it, thus deepening the problems, showing that it is not measuring the magnitude of the crisis. There is no prospect that exports, remittances, tourism, capital inflows, will grow again as before the crisis, so by not changing economic policy, the crisis will be prolonged. The article proposes to rethink our insertion into globalization, as economic policies to combat the pandemic and to achieve sustained growth with full employment.

Keywords: Pandemic, Crisis, fiscal deficit, fiscal austerity, monetary expansion.

Sumario: I. Se enfrenta una crisis similar a la de la Gran Depresión de 1929-1933; II. La respuesta de los países desarrollados al impacto económico del Covid-19; III. Comportamiento de los bancos centrales en los países desarrollados; IV. Los Créditos Swaps, los DEG y la postergación del pago de la deuda a los países más pobres; V. Ausencia de cooperación internacional real a favor de las economías más débiles; VI. La respuesta de los gobiernos de los países en desarrollo está siendo diferente a la de los países desarrollados; VII. La economía mexicana vulnerable al contexto internacional; VIII. 
La política monetaria y fiscal no han respondido en la magnitud necesaria para hacer frente a la crisis que enfrentamos; IX. Créditos del gobierno a las MiPymes y los problemas de insolvencia; X. La dificultad de superar la pandemia y retomar el crecimiento, lleva a que la crisis no sea temporal; XI. El Covid-19 cuestiona la globalización y las políticas que le acompañan; XII. El gobierno debe asumir el papel rector de la actividad económica; XIII. Política fiscal, monetaria y cambiaria para el crecimiento y el empleo; XIV. Fuentes consultadas.

I. Se enfrenta una crisis similar a la de la Gran DePREsión de 1929-1933

1 政 $\begin{aligned} & \text { Grentamos una crisis económica que no se ha visto desde la } \\ & \text { Gran Depresión de 1929-1933. En } 1932 \text { la economía mexi- } \\ & \text { cana se contrajo } 14.8 \text { por ciento La pandemia del Covid-19, }\end{aligned}$ ha frenado el abasto de insumos provenientes del exterior y cerrado plantas productivas, lo que ha parado la producción mundial. La internacionalización de los procesos productivos, que abarataron costos e incrementaron ganancias por décadas, sobre todo a las empresas transnacionales, ha terminado generando una crisis, que llevará años superar y todo apunta que tendrá que replantearse las cadenas productivas por lo que las cosas no volverán a ser como eran antes.

La respuesta a la crisis de los gobiernos de los países desarrollados, ha sido flexibilizar la política monetaria y fiscal, tal como lo hicieron en la crisis de 2008-2009, y mantuvieron las mismas políticas económicas que la generaron. Ello llevó a que prosiguiera el bajo crecimiento, la vulnerabilidad y fragilidad, incapaces de sortear los problemas derivados de la pandemia del Covid-19 y de ahí la crisis de magnitud que se está presentando. 
La salida de la crisis de 1929-1933 implicó cambio drástico del patrón de acumulación, donde el New Deal instrumentado por el presidente Roosevelt de Estados Unidos, colocó al Estado como rector de la economía, subordinó al sector financiero a favor del gobierno para que éste instrumentara políticas de pleno empleo y a favor del sector productivo. Tal estrategia de crecimiento se implementó en la mayoría de los países y configuró condiciones de crecimiento desde fines de los años treinta hasta 1981 a nivel mundial.

La pandemia ha puesto de manifiesto las deficiencias del sector salud a nivel mundial, debido al predominio de las políticas de austeridad fiscal que han desatendido a dicho sector. Asimismo, cuestiona la alta interdependencia de insumos productivos en que se ha caído debido al libre comercio.

La crisis del Covid 19 ha acentuado las críticas a la globalización, ya que pasó a evidenciar la fragilidad de las economías, dada su dependencia respecto a importaciones, exportaciones, remesas, turismo, flujos de capital, que al verse afectados por la pandemia, por la interrupción de las cadenas de suministro internacionales, se frenaron los procesos productivos, como el sector servicios asociado al turismo, como la entrada de capitales. Ello aumenta el déficit de cuenta corriente, desestabiliza el mercado de capitales y de divisas y ha llevado a la gran mayoría de las economías a la crisis.

De ahí que la crisis actual tendrá que llevar a los gobiernos a replantear el proceso de globalización y las políticas que le acompañan, causantes de la problemática actual.

El problema se acentúa en aquellos países que no cuentan con manejo de la política económica para encarar los embates del virus y la problemática económica que se deriva de todo ello.

Cuando se presenta la pandemia en México, la economía ya enfrentaba caída de consumo, de la inversión privada y del gasto público debido a la política de austeridad fiscal predominante. A los problemas que las empresas ya enfrentaban, se suma el desabasto de insumos importados originado por el cierre de empresas de los 
países abastecedores, debido a la cuarentena para hacer frente a la pandemia. Ello viene aparejado a la caída de las exportaciones, de las remesas, del turismo internacional, por lo que se frena más la producción, lo que reduce sus ingresos, en contexto donde enfrentan alta deuda, y no ven perspectivas de apoyo gubernamental. Ello está ocasionado cierre de empresas y fábricas, lo que agrava los problemas del sector productivo, del sector externo, como de las finanzas públicas y privadas y configura un contexto de crisis y creciente desempleo. Ello va aparejado a la caída del mercado de capitales y de divisas, aumento de la insolvencia que desestabilizará el sistema bancario, lo que restringirá los flujos de capitales, como la disponibilidad crediticia.

Conforme no se erradique la pandemia y no cambie la política económica, continuará el cierre de empresas con la consecuente caída de la producción y aumento del desempleo, lo que es preocupante, pues llevará años restablecer la actividad económica.

II. LA RESPUESTA DE LOS PAÍSES DESARROLLADOS AL IMPACTO ECONÓMICO DEL COVID-19

La economía estadounidense se contrajo a un ritmo anual del 5 por ciento en el primer trimestre de 2020. En el mes de abril la producción industrial cayó $11.2 \%$ y la producción manufacturera cayó $13.7 \%$, siendo la caída más aguda en su historia. Desde finales de marzo a fines de mayo de 2020, 42 millones de trabajadores han solicitado ayuda por desempleo en dicho país. Y la tasa de desempleo en abril fue $14.7 \%$ y en mayo fue de $13.3 \%$, máximos históricos desde la Segunda Guerra Mundial. (Datos del Departamento de Comercio de Estados Unidos)

El PIB de Francia e Italia cayó en 5.3\% en primer trimestre del 2020. El Banco Central de Europa (BCE) anunció el 4 de junio que prevé una caída del 8.7\% en el PIB de la zona euro en 2020. 
Ante el cierre de empresas y el creciente desempleo que está originando la pandemia, la mayoría de los gobiernos han roto los paradigmas convencionales de austeridad fiscal y están procediendo a incrementar el gasto público en forma significativa, para el combate a la pandemia, como para apoyar a las empresas, al empleo y familias. Están otorgando subsidios y apoyos a las empresas, permitiendo postergar el pago de sus deudas, como aplazar el pago de impuestos siempre que mantengan a sus trabajadores.

Los gobiernos de los países desarrollados, a través del seguro del desempleo y otros programas, están apoyando los que están quedando desempleados y a los que ven disminuidos sus ingresos, para que guarden cuarentena, mantengan demanda y niveles de consumo. Con la finalidad de mantener la planta productiva y el empleo, países como Canadá, Dinamarca y otros cubren hasta el $75 \%$ de los salarios de las pequeñas y medianas empresas. El gobierno de Inglaterra está pagando hasta el 80\% de los salarios de los trabajadores hasta un tope de 2,500 libras al mes.

Hay países que han eliminado el impuesto a las nóminas y han instrumentado grandes paquetes de estímulo fiscal. No pueden dejar quebrar a las empresas, pues se comprometería el crecimiento potencial y la generación de empleo, donde todos saldrían perdiendo.

A raíz que Francia, Alemania y otros países empezaron a nacionalizar empresas cruciales para evitar su cierre y despidos masivos, dada la importancia que tienen en la actividad económica, el Consejo Económico Europeo pasó a autorizar a los países miembros que nacionalicen empresas estratégicas a fin de evitar que entren en quiebra.

Todos los países desarrollados están incrementando el gasto público deficitario, sin incrementar impuestos y muchos de ellos sin preocuparse de cómo lo van a financiar, o de cómo van a cubrir la deuda que están emitiendo.

El Congreso de Estados Unidos desde fines de marzo a mediados de mayo de 2020 ha aprobado paquetes de estímulo por 5 billones 
de dólares para ayudar a familias y empresas para superar la crisis. Por su parte, la Reserva Federal (Fed) ha bajado la tasa de interés a 0.0 y $0.25 \%$. Ha inyectado liquidez a los mercados y a la banca para que otorgue crediticios para apoyar a empresas, emprendedores, familias y gobiernos estatales. Los recursos desembolsados entre el Gobierno y la Fed rebasan los apoyos otorgados en la crisis de 2008-09. Señala Ghosh que "desde marzo, el gobierno de EE. UU. ha anunciado un gasto adicional de más del 14\% del PIB. En Japón, la cifra supera el 21\%, en comparación con casi el 10\% en Australia y alrededor del 8.4\% en Canadá" ${ }^{2}$. Por su parte dicen Sheng y Geng que la Oficina de Presupuesto del Congreso en Estados Unidos proyecta un déficit fiscal de 17.9\% del PIB - en 2020"3. Hay que recordar que el déficit fiscal de EUA en 2009 fue de 10\% del PIB.

El gobierno de EUA está enviando cheques a todos los ciudadanos. Ha detenido los desalojos de casas ante el incumplimiento de pagos de las hipotecas. Sin embargo, tales medidas encaminadas a evitar cierre de empresas y fuerte caída de demanda, están lejos de ser suficientes para proteger a los económicamente vulnerables, mientras no se resuelvan los problemas del fuerte desempleo.

La Unión Europea desde marzo de 2020 está flexibilizando en alguna medida su política fiscal y monetaria para apoyar a las empresas privadas y a los trabajadores y desempleados. Se están otorgando garantías crediticias, préstamos y subvenciones, y recursos específicos solo para el combate a la pandemia.

Los países más débiles de Europa vienen pidiendo la emisión de bonos europeos (que tengan el respaldo de todos), para tener mayor capacidad de gasto, pero los países del norte, se oponen, pues no quieren asumir el costo si los del sur caen en insolvencia. Se frenan los recursos a las economías más débiles, y los créditos y los condi-

${ }^{2}$ Ghosh,J., "Messages from "Fiscal Space", 2020, en www.project-syndicate.org, May 13

${ }^{3}$ Sheng, A. y Geng, X., Cooperate with China or Suffer, 2020, en www.project-syndicate.org, Mayo 28. 
cionan a la instrumentación de políticas de austeridad fiscal ${ }^{4}$.

El 27 de mayo 2020, la Comisión Europea propone un plan de recuperación de 750 mil millones de euros (500 en subvenciones y 250 en préstamos), que se suman a los 540 mil millones que ya habían sido aprobados por el Mecanismo Europeo de Estabilidad. Ello es tanto para recapitalizar empresas, como para proteger trabajadores y la salud. El fondo de $750 \mathrm{~mm}$ de euros tiene que ser recuperado a través de emisión de bonos y con nuevos impuestos. Ello refleja que no hay política fiscal que represente recursos adicionales que vayan a incrementar demanda para impulsar la dinámica económica y el empleo.

Cada vez hay más países europeos (ya suman 20) que otorgan renta mínima a su población, que va de los 200 euros en Polonia a 2000 en Luxemburgo ${ }^{5}$. Sin embargo, ello no contrarresta los niveles salariales que perdieron los que han quedado desempleados.

Como en todo proceso, hay sectores que se oponen a los déficit públicos y quieren condicionar los apoyos a que instrumenten políticas de mayor privatización de sus sectores estratégicos, así como reformas laborales y de los sistemas de pensiones, que pasa a actuar en detrimento de los derechos laborales y el nivel de vida de los trabajadores.

ili. Comportamiento de los bancos centrales en los PAÍSES DESARROLLADOS

La expansión del gasto público es acompañado por sus bancos centrales que han bajado la tasa de interés a niveles cercanos a cero (Japón y Alemania ya venían trabajando con tasas de interés negativas por los problemas que enfrentaban) y proceden a comprar la deuda

${ }^{4}$ Véase a Mitchell, W., The European Commission non-stimulus is a waiting game before new austerity is imposed, 2020, en http://bilbo.economicoutlook.net/blog/, Abr. 27.

${ }^{5}$ wrere.elmundo.es, 30 de mayo 2020. 
pública en los mercados secundarios, para que la banca tenga liquidez para que siga comprando deuda del gobierno. Señalan Sheng y Geng que "la Reserva Federal de EE. UU. ha desatado una relajación monetaria sin precedentes (ampliando su balance en casi 3 billones de dólares a mediados de mayo" •. (2020) Ello se hace con el fin de aumentar gasto público y demanda interna, para contrarrestar la caída de exportaciones y de la inversión y consumo interno.

Por lo general, los rescates gubernamentales y de los bancos centrales siempre se dirigen a favorecer al sector financiero a pesar de que la causa de la crisis actual no deviene de dicho sector como en 2008-2009. Este sector pasa a ser afectado ante la caída de las bolsas por las expectativas negativas conformadas en la economía mundial por la pandemia, como por los problemas de insolvencia que se presentan, tanto por la desvalorización de los activos financieros, como por la caída de ingresos de las empresas y familias, por el cierre de empresas, caída de producción, de ventas e ingresos.

El apoyo al sector financiero ha permitido que se recupere en parte la caída del precio de las acciones. El mercado de capitales se ha venido recuperando. El 27 de abril mostraba un 30\% por arriba del nivel mas bajo de marzo $^{7}$, lo que amortigua en parte los problemas financieros, aunque éstos siguen por la contracción de la producción y de la demanda. por lo que hay quienes señalan que no se caerá a una crisis como la de la de 2008-09. Ello dependerá de que tanto dure la pandemia, tanto en EUA, como en el resto del mundo, así como de la política económica que se instrumente.

Ante la crisis que se enfrenta, algunos bancos centrales de los países desarrollados están instrumentando medidas no convencionales de compra directa de deuda de los gobiernos para que éstos financien sus gastos para combatir a la pandemia, como para apoyar a empresas e individuos y evitar una fuerte crisis. El banco

${ }^{6}$ Sheng, A. y Geng, X., op cit.

${ }^{7}$ O'Neill, J., Reading the COVID-19 Market, 2020, en www.project-syndicate.org, Abr. 29. 
central de Inglaterra a partir del 9 de abril de 2020, pasó a prestarle directamente al gobierno, sin la necesidad de emitir bonos, para permitirle gastar libremente, en forma temporal para encarar la pandemia y los problemas de la economía. El valor de la deuda actual es de $0.1 \%$. Nos dice Mitchell que "en lugar de que el banco central compre deuda en el mercado secundario, puede prestar directamente al gobierno"s.

El BCE ha dicho que hará lo necesario, pero impone condiciones a los países para recibir mayor liquidez ${ }^{9}$ Alemania y los países del norte de Europa, se oponen a que el BCE compre deuda directa de los países miembros, sobre todo de los más débiles, ante sus problemas de pago.

El BCE incrementó el 4 de junio de 2020 su programa de compras de bonos a 1.35 billones de euros (1.52 billones de dólares), desde los 750 mil millones de euros, que había ofrecido meses antes, para apoyar a los países que enfrentan déficits presupuestarios. Éstos déficit son no porque estén aumentando su gasto, sino sobre todo por la menor recaudación tributaria, como por el pago de sus deudas. De tal forma esa compra de deuda no es para impulsar la dinámica económica de tales países. Como señala Mitchell, la única función efectiva que realiza el BCE es evitar que los Estados miembros se vuelvan insolventes, lo que prolonga la vida de la moneda común" ${ }^{10}$. El BCE no les permite a los países miembros expandir el gasto deficitario en las magnitudes necesarias para generar empleo y crecimiento económico. El BCE señaló que se espera una inflación de 0.3 por ciento en el 2020, lo que refleja una situación de deflación en dicha zona, lo que frenará más su crecimiento económico.

${ }^{8}$ Mitchell, W., Bank of England official blows the cover on mainstream macroeconomics, 2020, en http://bilbo.economicoutlook.net/blog/, Abr. 28.

${ }^{9}$ Mitchell, W., Be careful not to get ahead of ourselves - hard-edged class struggle will be necessary, 2020, en http://bilbo.economicoutlook.net/blog/, Abr. 8.

${ }^{10}$ Mitchell, W., Eurozone inflation heading negative as the PEPP buys up big - don't ask the mainstream to explain, 2020, en http://bilbo.economicoutlook.net/blog/, Jun. 4. 
De no comprar deuda pública el BCE a los estados miembros para que éstos puedan incrementar su gasto para encarar los problemas que enfrenan, habrá quienes (sobre todo Italia, dado su mayor nivel de politización) se salgan del euro y retomen su moneda para financiarse con ella. La salida de algunos de los países de la Unión Monetaria Europea debilitaría dicha zona. Toda crisis genera cambios significativos y ésta los va a ocasionar y Europa puede quedar debilitada y la colocaría en desventaja frente a EUA y China.

iv. Los Créditos Swaps, los DEG y La postergación deL PAGO DE LA DEUdA A LOS PAísES MÁS POBRES

En marzo de 2020, la Reserva Federal extendió líneas swaps de intercambio de divisas a 14 bancos centrales de economías en desarrollo (incluido México) para que éstos contasen con dólares y liquidez necesaria frente a las demandas de dólares que enfrentan. No se permite que tales recursos se canalicen al impulso del empleo y la dinámica económica, ante el temor que ello pueda ocasionar inflación y desestabilice más la moneda y se afecten los intereses del capital financiero invertido en tales países. Como señala Jayati Ghosh "estos intercambios reflejan los intereses nacionales estratégicos de los Estados Unidos y, por lo tanto, refuerzan los desequilibrios de poder globales" "Ello se hace para evitar que tales países caigan en moratoria del pago de sus deudas y cambien la política predominante que favorece al gran capital internacional.

El problema de los créditos swaps es que se están canalizando a las subastas de dólares que realiza el Banco de México para encarar la demanda por dólares que enfrenta para evitar presiones sobre el tipo de cambio. En el contexto de incertidumbre que vivimos, la demanda especulativa por dólares se incrementa y terminarán por agotarse dichos créditos, lo que le planteará un problema al gobier-

${ }^{11}$ Ghosh, J, The Pandemic and the Global Economy, 2020, en wrew.peri.umass.edu Abr. 20. 
no de cómo reembolsar los créditos swaps. Ello llevará a hacer uso de las reservas internacionales y/o de mayores créditos externos y esa historia ya la conocemos y siempre termina en crisis. Es decir, al acabarse esos créditos y las reservas internacionales, como aconteció en 1982 y 1994, no habrá viabilidad de cubrir el pago de la deuda externa, ni el déficit de comercio exterior, ni mantener la estabilidad peso - dólar, lo que acentúa la crisis.

Economistas como Gordon Brown y Lawrence H. Summers ${ }^{12}$ se han pronunciado por que el Fondo Monetario Internacional asigne Derechos Especiales de Giro (DEG) a los países en desarrollo para que encaren sus problemas. Tales recursos son sobre todo para hacer frente al pago de la deuda, por lo que solo postergan la manifestación de la insolvencia, pues no hay perspectivas de crecimiento de exportaciones y al continuar la misma política económica, seguirá reproduciendo la incapacidad de pago.

El G-20 decidió que se posponga el pago del servicio de la deuda a los países más pobres por seis meses o hasta fin del 2020 y otorgaron préstamos adicionales para que cubran contingencias, pero condicionados a que no haya cambios de política económica. Ello impide instrumentar políticas a favor del crecimiento económico y del empleo, por lo que no se configuran condiciones de pago de la deuda y la postergación de pagos no les ayuda para superar la crisis, por lo que ésta continuará y acentuará las diferencias económicas entre las economías exitosas y las menos desarrolladas.

\section{v. Ausencia de coOperación internacional Real a favor DE LAS ECONOMÍAS MÁS DÉBILES}

Ante la creciente ramificación de la pandemia y la fuerte caída de la actividad económica, no se manifiesta política de cooperación de las potencias exitosas, hacia las menos desarrolladas. En vez de

${ }^{12}$ Brown, G. y Summers, L. H., Debt Relief Is the Most Effective Pandemic Aid, 2020, en wwr.project-syndicate.org, Abr. 15. 
cooperación entre países de transferencia de recursos financieros baratos y ayuda para el combate a la pandemia, crece el individualismo y el nacionalismo que ya venia aconteciendo. Cada país vela por si mismo y quiere crecer a costa del vecino.

China está mandando medicamentos a algunos países dentro de su estrategia de adquirir mayor número de clientes comerciales para su expansión. Pero no se presenta apoyo financiero sin condiciones para superar los problemas que se enfrentan.

Los estragos que la pandemia está ocasionando en EUA, en termino de número de contagios y muertes, como por la contracción económica y alto desempleo, su gobierno acentúa el conflicto con China, ante la pérdida creciente de hegemonía mundial que está sufriendo frente a China. EUA culpa a este país de la propagación del Covid-19 y continúa imponiéndole políticas proteccionistas, así como restricciones tecnológicas a la empresa Huawei.

Las instituciones financieras, más allá de permitir a los países africanos más pobres que posterguen el pago de la deuda hasta inicios del 2021, tampoco están soltando dinero en magnitudes suficientes a los países que lo necesitan, que son la gran mayoría, por lo que los problemas de éstos seguirán.

Los países pobres, como los llamados países en desarrollo, requieren de apoyo de las economías con mayor nivel de desarrollo, tanto para combatir la pandemia, como para frenar la contracción económica y el alto de desempleo.

Mientras no haya trabajo conjunto para el combate a la pandemia, como para frenar la crisis económica a través de transferencias financieras y tecnológicas a bajo costo y mejores tratos comerciales, más se tardará en erradicar la pandemia, como la salida de la crisis. Un país por si solo no podrá retomar una dinámica sostenida, si la mayoría de la economía mundial sigue con fuertes problemas económicos y de pandemia. 
La cooperación internacional es importante en el combate a la pandemia, como para preservar el ecosistema. Debe haber solidaridad internacional para apoyar a los países pobres con equipo e instrumentos médicos, como con recursos para garantizar niveles de ingreso para frenar la epidemia y evitar mayores niveles de miseria en éstos.

Los países acreedores tienen que aceptar la postergación del pago de la deuda por parte de los países menos desarrollados hasta que éstos tengan condiciones de crecimiento y de pago. De no darse esta cooperación, seguirá la prolongándose y ramificándose a nivel mundial, lo que hace más difícil salir de la crisis.

\section{Vi. LA RESPUESTA DE LOS GOBIERNOS dE LOS PAÍSES EN DESARROLLO ESTÁ SIENDO DIFERENTE A LA DE LOS PAísES DESARROLLADOS}

Los países subdesarrollados enfrentan caída de sus exportaciones, de su precio y volumen, así como salida de capitales, devaluación de sus monedas, caída de sus mercados de capitales, encarecimiento de su deuda externa en términos de su moneda, que presiona sobre las finanzas de los sectores endeudados. Se contrae la producción y aumenta el desempleo, lo que presiona hacia abajo los salarios, lo que disminuye más la demanda y la actividad económica. El problema se agrava debido a que no cuentan con condiciones productivas, financieras y de política económica para encarar tal situación.

En esos países predominan las políticas de austeridad fiscal, de libre comercio, que han ocasionado rezagos productivos, baja productividad, aumento de la economía informal, desatención y privatización de los servicios públicos (donde sobresale el del sector salud), que han colocado a estos países en un contexto de debilidad para hacer frente a los estragos que está ocasionando el Covid-19.

El proceso de más mercado, menos Estado que viene desde los años ochenta en la mayoría de las economías latinoamericanas, que 
ha impulsado las asociaciones público - privada, ha llevado a descuidar y privatizar la infraestructura y los sectores estratégicos de muchas economías. También han rezagado, delegado y subcontratado servicios públicos, que han resultado inoperantes para otorgar servicios requeridos a la población.

La pandemia del coronavirus está evidenciando que los sistemas de salud en muchos países están incapacitados para encarar y superar el virus, como consecuencia de cómo las políticas de austeridad han atentado sobre los servicios públicos. Resalta la incapacidad presupuestal para adquirir medicamentos, para hacer pruebas, para equipar a médicos y enfermeras y personal de los hospitales para evitar su contagio y dar mejor atención a los contagiados.

A ello se suma el hecho que las aglomeraciones de la población son mayores en los países menos desarrollados, por lo que el contagio tiende a expandirse más. Asimismo, un alto porcentaje de la población económicamente activa está en la economía informal y vive al día, como resultado de las políticas económicas predominantes, por lo que les es difícil guardar cuarentena para protegerse y frenar el contagio y la pandemia. Su población padece de problemas de diabetes, obesidad, desnutrición, que los hacen más vulnerables a la pandemia, y sus servicios de salud son insuficientes para encararla. Ello hará que a estos países les llevará más tiempo superar la pandemia, como salir de la crisis económica están enfrentando.

Las economías subdesarrolladas tienen menos condiciones para encarar los problemas, respecto a los países desarrollados. Si en éstos está habiendo miles de muertos y están viendo restringida su actividad económica, peor situación enfrentarán las economías menos desarrolladas. Estos países no cuentan con los recursos requeridos, ni manejo de política monetaria y fiscal para encarar la pandemia, ni mantener la planta productiva, y mucho menos para impulsar las reestructuraciones a sus procesos productivos que exigirán las nuevas reglas de comportamiento que se establezcan después de la pandemia. 
Las economías menos desarrolladas aducen que no tienen márgenes de maniobra para flexibilizar la política económica, por lo que su respuesta monetaria y fiscal pasa a ser restringida. Ello se debe a que dependen de la entrada de capitales, lo que les exige asegurarles condiciones de rentabilidad a través de altas tasas de interés, austeridad fiscal y estabilidad cambiaria y no se atreven a cambiar dichas políticas.

VIII. LA ECONOMÍA MEXICANA VULNERABLE AL CONTEXTO INTERNACIONAL

La pandemia y la caída de la actividad económica mundial, llegó cuando la economía nacional ya venía decreciendo. En 2019 el PIB cayó en $0.1 \%$, por lo que tales problemas nos afectarán más, dada la incapacidad productiva, de servicios médicos y de política económica para hacerles frente.

Las políticas predominantes de austeridad fiscal y libre movimiento de mercancías y capitales relegaron la ciencia y tecnología, al sector productivo, la generación de empleos formales, así como la atención de los servicios médicos del sector público y de educación, lo que ha configurado bajo crecimiento económico, desequilibrios productivos y en el sector externo, llevando a la economía a depender de la entrada de capitales, a tener altos niveles de endeudamiento, de desempleo y miseria, lo que nos debilita para encarar la crisis que enfrentamos.

El bajo crecimiento que ha caracterizado a la economía en las últimas décadas, se venía sustentando en las exportaciones, como en las remesas y en entrada de capitales.

Las políticas encaminadas a atraer capitales, como alta tasa de interés y austeridad fiscal, actúan en detrimento de la capacidad productiva, del empleo, como del ingreso de empresas e individuos, lo que mantiene restringido el mercado interno y nos coloca más a merced del comportamiento de la economía mundial y los inversionistas externos. 
Por más que el gobierno venía diciendo que mantenía la estabilidad económica (finanzas 'sanas', sector externo financiable y estabilidad cambiaria) y que ello nos protegería frente adversidades externas, la pandemia pasó a evidenciar la fragilidad de dicha estabilidad. Ello no podía proteger la economía frente a los shock externos, debido a que se sustentaba en el comportamiento del crecimiento de las exportaciones, la entrada de capitales, el turismo y las remesas. De ahí que al contraerse las exportaciones (las exportaciones de México a EUA en el mes de abril en relación al mes de marzo cayeron en 44.4\%), como el precio internacional del petróleo, la entrada de capitales (la inversión extranjera directa registrara una caída de 26 por ciento en el primer trimestre del año, comparada con igual periodo de 2019), las remesas (cayeron 28.5\% en abril en relación a marzo, datos del INEGI), la economía cae en crisis, pues no tiene condiciones endógenas, ni manejo soberano de la política económica que contrarresten tales problemas. Cabe destacar que datos del Banco de México indican que al cierre de 2019 los valores gubernamentales en manos de residentes en el extranjero ascendían a 2 billones 148 mil 286 millones de pesos y que al 10 de junio pasado (cifra disponible más reciente) habían bajado a un billón 846 mil 234 millones (Datos de Banxico). Es decir, en los primeros cinco meses del año inversionistas extranjeros han retirado del país capitales por alrededor de 300 mil millones de pesos.

En consecuencia, ha caído la producción, tanto por el desabasto de insumos importados, como por la cuarentena, aunado a la caída de exportaciones, menor entrada de capitales y salida de éstos de la economía. El Indicador Global de Actividad Económica (IGAE) del Inegi muestra que la economía mexicana cayó 19.7\% en abril, respecto a marzo. Las actividades secundarias cayeron $25.1 \%$, las terciarias $14.4 \%$ y las primarias descendieron $6.4 \%$. En abril, la industria de la construcción tuvo una caída de 38.4 por ciento anual.

Los desequilibrios productivos y macroeconómicos, sobre todo el déficit de cuenta corriente, salen a flote con la crisis de la pandemia, 
ya que ésta ha frenado los flujos de capital para financiarlos, por lo que se devalúa la moneda, frena la actividad económica y compromete el financiamiento del déficit de cuenta corriente y con ello la libre movilidad de mercancías y capitales.

VIII. LA POLÍtICA MONETARIA Y FISCAL NO HAN RESPONDIDO EN LA MAGNITUd NECESARIA PARA HACER FRENTE A LA CRISIS QUE ENFRENTAMOS.

En los Criterios Generales de Política Económica presentados por el gobierno al Congreso de la República el 8 de septiembre de 2020, se contempla una estimación de superávit primario de $0.2 \%$ del PIB para el 2020, después de haber tenido un superávit primario de $1.1 \%$ en 2019, lo que evidencia que se mantiene la restricción fiscal, debido a que el gobierno sigue gastando menos de lo que recauda (excluyendo el pago del servicio de la deuda), por lo que no se aplica política contra-cíclica que revierta la caída de exportaciones, de remesas, de entrada de capitales, del consumo e inversión privada. Las exportaciones en el mes de julio de 2020 en relación a igual mes de 2019 traían una caída de 8.9\%. La Inversión Fija Bruta se hundió 38.4\% en el mes de mayo del 2020, respecto al mismo mes de 2019. El consumo privado mostró una caída de 23.5\% en el mes de mayo de 2020, respecto al mismo mes del 2019 (Datos del INEGI) El programa del gobierno frente al coronavirus y los efectos negativos que tiene en la economía, representa (según el secretario de Hacienda) entre el 1 y $1.5 \%$ del PIB. Piensa que con ello se superarán los problemas. Ello refleja que no está dimensionando el impacto negativo de la crisis, y de ahí su pobre respuesta a ésta, por lo que no está asumiendo el papel que le corresponde, lo que ha llevado a que en el segundo trimestre del 2020 el PIB muestre una caída de $18.7 \%$ respecto al mismo período de 2019. (INEGI)

Como se señaló antes, los países desarrollados trabajan con altos déficit fiscales, y países de América Latina también están flexibili- 
zando su política fiscal. El déficit fiscal en Perú será del 9\%, en Brasil el 8\%, en Chile el 5.5\%, en Argentina el 3.5\%, y en Colombia el $2.8 \% .^{13}$

El gobierno mexicano, al restringir el gasto público para no caer en déficit fiscal y más deuda, está dando una inadecuada respuesta de política económica a los problemas que enfrentamos, debido a su sometimiento a las calificadoras internacionales y a los preceptos básicos del neoliberalismo, tal como la autonomía del banco central (que no compra deuda pública en forma directa al gobierno), austeridad fiscal y libre movilidad de mercancías y capitales, que le impiden flexibilizar la política monetaria y fiscal a favor del crecimiento. De ahí el porque insiste en recortes presupuestales y en no bajar la tasa de interés para evitar salidas de capitales y presiones sobre el tipo de cambio, por lo que deja de tener márgenes de maniobra para tener políticas monetaria y fiscal para contrarrestar la caída de la demanda externa e interna, por lo que se profundiza la contracción económica.

Las autoridades monetarias y hacendarias no saben como encarar los problemas que la economía nacional enfrenta, y las políticas que instrumentan contraen más la actividad económica, aumentan el desempleo y la pobreza. Ello refleja o incompetencia, o simplemente que no quieren quedar mal con los dueños del dinero, que son los favorecidos de dichas políticas. Ni siquiera toman como referencia lo que los otros países están haciendo para enfrentar sus problemas.

Los economistas convencionales parten del precepto de que el gobierno gasta en función de sus ingresos tributarios, de ahí que el gobierno insiste en que las empresas deben pagar impuestos para que el gobierno pueda gastar. El problema es que las empresas no pueden pagar impuestos dada la caída de sus ventas e ingresos deri-

${ }^{13}$ Elgin, Basbug y Yalaman, Economic policy responses to a pandemic, Center for Economic Policy Research (CEPR), 2020, 10 de Mayo de 2020. 
vado de la contracción económica y del hecho que el gobierno gasta poco. Al gastar poco, frena la actividad económica, así como el ingreso de empresas e individuos, por lo que éstos no tienen condiciones de pagar impuestos, ni su deuda, por lo que piden postergar dichos pagos. Si las empresas pagan impuestos para no ser sujetos de multas, lo hacen a costa de disminuir inversión y consumo, lo que ahonda más la contracción económica y el gobierno terminará recaudando menos.

El gobierno con su filosofía de no rescatar a los de arriba, sino apoyar a la gente pobre, está desatendiendo a la esfera productiva. El planteamiento falas que dice que lo de abajo sube a los de arriba y así favorece a la esfera productiva, no se da, pues lo que da a los de abajo, es insuficiente para incrementar demanda y para impulsar la producción y la generación de empleo. El INEGI reporta que el índice global de las remuneraciones de los sectores económicos en junio se encuentra 8.7 por ciento debajo de su nivel de 2019. Y que en el mes de junio el número de personal ocupado en empresas constructoras, manufactureras y comercio cayó 6.4 por ciento respecto al mismo mes de 2019.

El gobierno, en su afán de no incrementar la deuda, no está haciendo nada para evitar el cierre y quiebre de empresas y el mayor desempleo, lo que está contrayendo la capacidad productiva y la generación de riqueza y empleo, por lo que la crisis será prolongada, con graves consecuencias económicas, políticas y sociales.

El gobierno mexicano no tiene preocupación alguna de cambiar la política económica predominante. No tiene interés en romper con los paradigmas convencionales y llegar acuerdo o legislar para que el banco central le compre deuda al gobierno para que éste pueda incrementar el gasto para hacer frente a quejas de los Estados y Municipios que han visto reducida la partida de las Participaciones Federales y Aportaciones, como para apoyar a empresas y generar empleo. De responder el gobierno a ello, impulsaría la actividad económica y vería incrementada su recaudación tributaria, lo 
que le permitiría reducir el déficit fiscal y el monto de la deuda que haya emitido para gastar.

El gobierno solo se aboca a políticas sociales a costa de recortar el presupuesto en otras partidas y trata de combatir la corrupción, como si esto fuera el combate al neoliberalismo, el cual continúa, lo que refleja una postura de subordinación a las reglas del juego impuestas por los organismos financieros internacionales.

$\mathrm{Al}$ restringir el gobierno el gasto e inversión, tratando de generar excedentes presupuestarios para reducir la deuda pública, contrae más la actividad económica y aumenta más el desempleo. Ello restringe el ingreso de empresas e individuos, por lo que gran parte de la población no guarda la cuarentena. Ello lleva a que prosiga el contagio y se incremente el número de muertes, y se frene de nuevo la actividad económica en varios sectores y la actividad económica. En menor ingreso nacional disminuye la recaudación tributaria, lo que impide alcanzar el bajo déficit fiscal que busca, por lo que aumenta la deuda pública sin haber incrementado el gasto. Los ingresos tributarios que contemplaba la Ley de Ingresos para el 2020 eran 3 billones 626 mil millones de pesos, y lo estimado que se recaudará a fines del 2020 serán 3 billones 343 mil millones de pesos y la deuda pública interna en valores gubernamentales pasará de ser 53.4\% del PIB en 2019, a ser 54.4\% en el 2020. (Datos de los Criterios Generales de Política Económica para la Iniciativa de Ley de Ingresos y el Presupuesto de Egresos de la Federación al Ejercicio Fiscal 2021, Pags. 51 y 62)

El gobierno de México no esta dimensionando la magnitud de los problemas que enfrentamos. El gobierno debe responder a los reclamos nacionales, de crecimiento económico y empleo, para lo cual debe retomar el manejo soberano de la política económica. 
ix. Créditos del gobierno a las MiPymes y los problemas DE INSOLVENCIA

El gobierno anunció que otorgarán 2 millones de microcréditos de 25 mil pesos a negocios familiares a una tasa de interés del 6.0 por ciento a un plazo de 36 meses, con un plazo inicial de gracia de tres meses y otro millón de créditos hipotecarios a través del INFONAVIT y FOVISSSTE. Sin embargo, estos créditos no serán de gran ayuda, pues la economía enfrenta caída de ventas e ingresos.

Los microcréditos que otorga el IMSS son solo para las microempresas formales y para ser sujetos a ellos tienen que no haber desocupado a sus trabajadores y resulta que la mayoría no ha mantenido a los trabajadores, por lo que no son sujetos de crédito, lo que empeora mas su situación, por lo que muchas terminan por cerrar y darse de baja, como ha venido aconteciendo, evidenciando que tales créditos no vendrán a apuntalar la actividad productiva. Los 25 mil pesos de crédito a las microempresas son sobre todo atractivos para los informales, los que no están en el IMSS y no son sujetos de esos créditos, solo los que fueron censados durante la campaña del 2018.

Ante la caída de ventas e ingresos, lo que menos quieren las pequeñas empresas son créditos, pues no tendrán como asegurar el reembolso de la deuda. Ante los problemas de cartera vencida, la banca ha acordado dar períodos de gracia entre cuatro y seis meses, eliminando intereses y comisiones y a su vez la Comisión Nacional Bancaria y de Valores autorizó a los bancos, cambios temporales en sus contabilidades para que ello no redunde en balances negativos.

El problema es que la reestructuración de la deuda a la cual están recurriendo las empresas, de poco les servirán, pues no hay perspectivas de ver incrementadas sus ventas e ingresos, para cubrir sus obligaciones financieras, dado el predomino de la política de austeridad fiscal y la alta tasa de interés, como por la contracción de la economía mundial. 
El predominio de altas tasas de interés incrementa la carga del servicio de la deuda, lo que acentúa los problemas financieros de los deudores. Al aumentar la cartera vencida, la banca se hace más cauta en el otorgamiento del crédito. Si no ven perspectivas de crecimiento y de recuperar el crédito no lo otorgan y tal es la situación que predomina actualmente. De hecho, las empresas no quieren crédito, pues ello las sobre endeudan y no hay perspectivas de crecimiento. Lo que quieren es que el costo de la deuda disminuya y que el gobierno incremente el gasto público para así aumentar sus ventas e ingresos y poder pagar su deuda y retomar la inversión.

Para evitar caer en insolvencia, el ingreso de los deudores tiene que crecer por arriba del costo de la deuda, situación que no acontece con la política que el gobierno y el banco central instrumentan.

$\mathrm{Al}$ entrar la banca en problemas de insolvencia, el gobierno no podrá entrar al rescate de la banca a fin de no comprometer sus objetivos de austeridad fiscal y no incremento de deuda. De actuar a favor de la banca, la población lo cuestionará, de por qué rescataría a la banca y no a los desempleados y a las empresas que están quebrando.

X. LA DIFICULTAD DE SUPERAR LA PANDEMIA Y RETOMAR EL CRECIMIENTO, LLEVA A QUE LA CRISIS NO SEA TEMPORAL

Ha caído la producción, tanto por desabasto de insumos, como por la cuarentena, así como por la caída de demanda interna y externa y por falta de apoyo a las empresas para evitar su quiebre, como apoyo a los trabajadores y desempleados para que guarden cuarentena para frenar la pandemia. Está disminuyendo la esfera productiva, el comercio internacional, hay aumento de la deuda pública y privada, por lo que no será fácil retomar el crecimiento. En los próximos años continuará la recesión, el desempleo, los problemas de cartera vencida, la mayor desigualdad del ingreso, que prolongarán tal problemática de no revertirse las políticas y situaciones que la han generado. 
No hay perspectivas de regresar a los niveles de producción y empleo previos a la Covid -19, dada la desaceleración de la economía mundial y la respuesta insuficiente realizada por las autoridades hacendarias y monetarias en nuestro país.

La reapertura de las actividades económicas no implicará que la economía retome el crecimiento y alcance los niveles que tenían antes de la pandemia, debido a que prosigue la pandemia, está aumentando la destrucción de planta productiva y cierre de empresas, así como la cartera vencida, que no será fácil revertir y superar, por lo que la recuperación económica no será en forma "V" (simétrica o asimétrica) como el gobierno dice.

Ante el bajo crecimiento que ha venido enfrentando la economía nacional, aunado a la caída de la inversión, como al proceso de desindustrialización, la economía presenta desgaste y obsolescencia del aparato productivo, que la coloca en una posición de debilidad para encarar los embates derivados del Covid 19. Además, para quien van a producir las empresas, si hay una fuerte caída de la demanda interna y externa y el gobierno mantiene restringido el gasto, sumado a los problemas financieros y la restricción y encarecimiento crediticio que tienen las empresas. Los problemas de oferta proseguirán, tanto por la escasez de productos importados y nacionales (por la cuarentena), como por la caída de la inversión y la producción nacional. No hay perspectivas de que la demanda interna aumente, dado el alto desempleo, como la fuerte caída de consumo e inversiones y la política de austeridad fiscal predominante. Tampoco hay perspectivas de que la demanda externa derivada de las exportaciones, las remesas, la entrada de capitales y el turismo, crezcan. El comercio mundial ya venía teniendo bajo crecimiento antes de la pandemia y menos crecerá ante la crisis mundial actual. Mientras no se retome la dinámica económica mundial no volverán a crecer las exportaciones, al igual que el turismo, por lo que las empresas vinculadas a ello, permanecerán cerradas o trabajando a baja capacidad cuando empiece a abrirse paulatinamente tal actividad. 
Muchos países instrumentarán políticas proteccionistas, por lo que no se alcanzará la dinámica de exportaciones que se tuvo hasta antes de marzo de 2020, por lo que varias ramas industriales y empresas tendrán que reestructurar sus procesos productivos para redirigir su producción hacia el mercado interno.

La economía nacional ha pasado a ser menos atractiva para recibir y retener captales, lo que complica el financiamiento del déficit de cuenta corriente y obliga a las autoridades a mantener el diferencial de tasas de interés con EUA, para que el capital no salga y siga fluyendo a la economía. De tal forma, la economía no puede instrumentar una política contra-cíclica para contrarrestar los embates externos, debido a que si baja la tasa de interés menos fluyen los capitales al país, y provoca la salida de los que están en el país. De igual forma, si aumenta el gasto público, ocasionaría presiones inflacionarias y sobre el tipo de cambio, que también provocaría salida de capitales y se complicaría el financiamiento del déficit de cuenta corriente. De ahí que no ha habido respuesta de la política fiscal, ni monetaria para contrarrestar el comportamiento negativo de las exportaciones, de las remesas, como de la entrada de capitales.

La crisis está disminuyendo la capacidad productiva. Se han acentuado los problemas estructurales de la economía. Hay descapitalización y desindustrialización, déficit de comercio exterior, déficit en las finanzas públicas y privadas, que merman más su capacidad de inversión y de gasto, acentuando ello la contracción económica y el desempleo. Ello incrementa los requerimientos de financiamiento interno y externo que no están disponibles, lo que ahonda más la crisis y no existe política económica interna que permita encarar tales problemas.

La crisis y la incertidumbre acentúan la salida de capitales y reducen la entrada de éstos, lo que desestabiliza el mercado de capitales y de divisas.

Banxico y Hacienda no están usando sus herramientas para encarar la crisis. El banco central mantiene altas tasas de interés y 
no compra deuda pública en forma directa para que el gobierno pueda incrementar el gasto a favor de los servicios médicos, de los desempleados, de los que viven al día, como para apoyar a las empresas para frenar el quiebre y cierre de éstas. El gobierno quiere evitar caer en déficit fiscal y en mayor deuda, a costa de sacrificar los propósitos nacionales de crecimiento, empleo y bienestar de la población, por lo que pasa a comprometer el crecimiento presente y futuro del país.

Mientras menos recursos se destinen a superar la pandemia y a apoyar a las empresas e individuos, menos posibilidad hay para salir de los problemas que se enfrentan. Las posiciones de varios gobiernos estatales de terminar con la cuarentena y que regresen trabajadores a varios sectores económicos para evitar fuertes caídas de la actividad económica y mayor desempleo, llevará a que siga propagándose la pandemia y el número de muertos.

\section{Xi. El Covid-19 cuestiona la globalización y las POLÍTICAS QUE LE ACOMPAÑAN}

Así como la globalización ha favorecido a las empresas transnacionales y a unos pocos países y la mayoría han sido perdedores, ahora la pandemia y la generalización de ésta y el freno de los procesos productivos que ha ocasionado, termina empeorando la situación para todos, aunque algunos países más que otros, en función de su capacidad para hacerle frente. Algunas enfrentan desindustrialización, rezagos productivos y no cuentan con manejo soberano de la política económica a favor del sector productivo y del empleo.

No se puede continuar con políticas que han actuado en detrimento de los factores endógenos de acumulación y nos han llevado a depender de las exportaciones y entrada de capitales, lo que nos colocan en un contexto de alta vulnerabilidad. La crisis es una oportunidad para modificar las políticas que la han generado, y cambiarlas para configurar las bases reales para alcanzar un crecimiento sostenido. 
No se puede proseguir con las mismas políticas económicas que han aumentado la vulnerabilidad de las economías en torno al comportamiento de la entrada de capitales. Llevará muchos años a la economía nacional recuperar la pérdida de capacidad productiva y de empleo que está aconteciendo. Y más se perderá y más tardaremos en recuperar lo perdido al no frenarse la pandemia y no cambiar la política económica causante de tal situación.

La superación de los problemas requiere de cambios significativos en toda la política económica que pasa por modificar la función y objetivos del banco central, como de la política fiscal, así como regular el movimiento de mercancías y capitales, como el comportamiento de la inversión que fluye al país para que transfiera tecnología a favor de empresas nacionales, que consuma insumos nacionales y respete el medio ambiente.

XII. El gobierno debe ASUMir EL PAPEL RECTOR de LA ACTIVIDAD ECONÓMICA

La salida de la crisis implicará revisar el papel del Estado en la economía, el cual tiene que replantear nuestra inserción en la globalización y retomar el manejo soberano de la política económica para responder a los objetivos nacionales de crecimiento, empleo y distribución del ingreso. Ello implicará reestructurar el proceso productivo, el funcionamiento del sector bancario-financiero, y las relaciones comerciales y financieras con el exterior.

La superación de la crisis económica requiere de fuertes y crecientes inversiones por parte del gobierno, por lo que debe romper con la austeridad fiscal. Tiene que recurrir al financiamiento interno, e impulsar los cambios legislativos correspondientes para que el banco central compre en forma directa al gobierno deuda pública a una tasa de interés cercana a cero, para que el gobierno impulse una actividad productiva encaminada a reducir el déficit de comercio exterior, como asegurar efectos multiplicadores internos a favor 
del ingreso de empresas e individuos para mejorar las finanzas del sector privado y el gobierno incremente su recaudación fiscal para encarar el pago de la deuda y reducirla.

El Estado no puede estar sumiso a los dictámenes de las agencias calificadoras y de los organismos financieros internacionales, sino debe asumir el papel rector que le corresponde y actuar como empleador de última instancia. Debe proteger la planta productiva, regular al sector bancario-financiero, como al sector externo, y ofrecer empleo a todo aquel que lo busca y no lo encuentra.

No se puede continuar con la política económica que configuró la crisis. Debe instrumentar aquellas políticas que permitan recuperar el crecimiento económico, con pleno empleo y estabilidad de precios. Los apoyos a las empresas van desde permitirles que posterguen el pago de impuestos y prestaciones, así como expansión del gasto público para que vean incrementada la demanda, así como préstamos preferenciales a bajas tasas de interés por parte de la banca de desarrollo. Los apoyos a las empresas deben están condicionados a que no despidan trabajadores, a que suspendan los dividendos a los accionistas, así como que cumplan con objetivos ecológicos.

Los problemas de la economía no se resolverán solo flexibilizando la política monetaria y fiscal a favor del combate a la pandemia y al impulso del sector productivo y del empleo. Se requiere cambiar el resto de la política, tal como el libre movimiento de mercancías y capitales y el funcionamiento del sector bancario, que han actuado en detrimento del sector productivo, como de la generación de empleo.

Se tiene que replantear los acuerdos comerciales de libre comercio, pues ello ha actuado en detrimento del sector manufacturero, ha reducido el crecimiento económico, ha aumentado el desempleo y subempleo, así como las presiones sobre el sector externo y los niveles de endeudamiento. Ha incrementado la economía informal y reducido los salarios, todo lo cual nos coloca en una situación de fragilidad para encarar la crisis derivada del Covid 19. 
La crisis mundial replanteará el proceso de globalización, debido a muchos países se encaminarán a asegurar la producción interna de insumos esenciales y estratégicos, tanto para evitar futuros desabastos ocasionados por pandemias y cuarentenas, como para impulsar su crecimiento e incrementar el empleo y reducir el déficit de comercio exterior y los requerimientos de entrada de capitales, ante la escasez de éstos. Señala Dalia Marin que "a medida que aumenta la pandemia de COVID-19, los riesgos inherentes a las cadenas de suministro mundiales son más evidentes que nunca”, lo que llevará a impulsar procesos de sustitución de importaciones para asegurar el abasto interno de insumos estratégicos. ${ }^{14}$

La inversión privada estará contraída mientras no se vean expectativas de superación de la pandemia y de la problemática económica. Para ello el gobierno debe instrumentar políticas económicas encaminadas a superar dichos problemas y no preocuparse por el equilibrio fiscal y por no endeudarse.

XIII. Política fiscal, MONETARIA Y CAMBIARIA PARA EL CRECIMIENTO Y EL EMPLEO

La política monetaria, fiscal y de tipo de cambio son fundamentales para incidir no solo en el comportamiento del gobierno en la actividad económica, sino para configurar condiciones de acumulación para impulsar la inversión privada y el empleo, como para establecer niveles competitivos a favor de la producción nacional y reducir el déficit de comercio exterior para alcanzar niveles de crecimiento más sostenidos y menos vulnerables del exterior. El gobierno tiene que dejar de lado las posiciones convencionales de que hay limites financieros y que tiene que trabajar con equilibrio fiscal. Ello ha limitado la actuación del gobierno en la economía, lo que se ha

${ }^{14}$ Marin, D., How COVID-19 Is Transforming Manufacturing, en www.project-syndicate. org, Abr. 3, 2020. 
traducido en menos Estado y más mercado, lo que ha acentuado la desigualdad del ingreso y la riqueza en el país y nos ha llevado a la crisis. Todo gobierno incrementar el gasto público deficitario para asegurar ingreso a los que están quedando desempleados, como para salvaguardar la planta productiva, generadora de riqueza y de empleo. Se requiere trabajar con un tipo de cambio flexible, competitivo que proteja la producción nacional frente a importaciones para preservar la planta productiva y la generación de empleo y evitar déficit de comercio exterior que frenan el crecimiento económico.

La crisis actual está llevando a muchos países a hacer uso de sus monedas, o regresar a las suyas (lo que tendrán que hacer los países de la zona euro), para poder financiarse con ellas. Un gobierno soberano gasta acreditando en la cuenta bancaria de los que le venden bienes y servicios y le dice al banco central que respalde dichas acreditaciones. Comúnmente, el gobierno emite deuda y la compra la banca comercial. El banco central compra la deuda pública a la banca comercial a través de acreditar en sus cuentas a través de un teclado. Y ahora dicha deuda está en posición del banco central, y éste, nos dice Mitchell, la puede cancelar a través de un teclado, de la misma forma en que la compró ${ }^{15}$. Pero en vez de pagar una tasa de interés en el mercado secundario para comprar la deuda pública, puede comprar la deuda directamente del gobierno, con tasa de interés cercana a cero, para que no represente una carga al gobierno.

El banco central tiene que satisfacer la demanda de créditos (acreditando en las reservas bancarias de los bancos) para que éstos satisfagan la demanda de créditos que enfrentan. Eso se hace a través de un simple teclado. Ello tiene que ir acompañado de una disminución significativa de la tasa de interés para bajar el costo del crédito y evitar problemas de insolvencia. Chile ha bajado su tasa

${ }^{15}$ Mitchell, W., The Bandwagon effect - caution not credit is needed, 2020, en http://bilbo. economicoutlook.net/blog/, Abr.9. 
de interés a $0.5 \%$, y no hay razón para que en nuestro país esté en $5 \%$ (julio 2020), lo cual solo favorece a la banca y afecta al resto de la economía, acentuando la recesión que ésta enfrenta, así como la desigualdad del ingreso a favor del sector financiero.

Mientras el banco central no baje la tasa de interés y compre deuda del gobierno ya sea directamente o en el mercado secundario, para que éste le compre deuda al gobierno, éste no podrá trabajar con gasto deficitario para atender las demandas de las empresas, de los desempleados y de los que han visto disminuidos sus ingresos. Debe romper con los candados macroeconómicos autoimpuestos de austeridad fiscal y de no incremento de la deuda.

Banxico debe apoyar al sector productivo y a la generación de empleo, a través de bajar la tasa de interés a niveles cercanos a cero, y debe regular al sector bancario y financiero para evitar especulaciones que distorsionen el funcionamiento de la economía y hacerlos funcional al sector productivo y al empleo.

El gobierno cuenta con mayoría en el Congreso para que se legisle para que el banco central le compre deuda al gobierno para que el gobierno incremente el gasto para el combate a la pandemia, para asegurar ingreso para aquellos que viven al día, como para preservar la planta productiva e incrementar el empleo.

Comúnmente economistas convencionales señalan que el gasto público deficitario ocasiona inflación y alzas de la tasa de interés y mayor deuda. Hay que señalar que el gobierno no puede gastar indiscriminadamente. El límite del gasto público está dado por los recursos reales con que cuenta la economía. El mayor gasto público no ocasionaría inflación, dados los altos niveles de capacidad ociosa y desempleo existentes por la drástica caída de exportaciones y del consumo interno. Lo importante es generar empleo, asegurar la planta productiva y aumentar la producción y productividad para poder satisfacer la mayor demanda que genere el incremento del gasto público y así evitar presiones inflacionarias y sobre importaciones y sobre el sector externo. La tasa de interés la determina el 
banco central en función de sus objetivos, los cuales deben compatibilizar baja inflación con alto empleo, como acontece en Estados Unidos y otros países. Al impulsar una dinámica económica que impulse el ingreso nacional y la recaudación tributaria por arriba del nivel de la tasa de interés, se cubre el pago de la deuda y ésta se reduce.

Es responsabilidad del gobierno crear el empleo que el sector privado no genera. La política social y los proyectos del gobierno (trenes, aeropuerto y refinería) son insuficientes para atender los reclamos de empleo que los desempleados demandan. El gobierno tiene que expandir el gasto público para preservar el empleo existente y para crear empleo necesario para los que lo buscan y no lo encuentran. Asimismo, el gobierno debe oponerse a los recortes salariales que están realizando ciertas empresas, pues ello acentúa la contracción de demanda y de la actividad económica, además de afectar el nivel de vida de los trabajadores.

\section{xiv. Fuentes Consultadas}

Brown, G. y Summers, L. H., Debt Relief Is the Most Effective Pandemic Aid, 2020, en wwr.project-syndicate.org.

Elgin, Basbug y Yalaman, Economic policy responses to a pandemic, Center for Economic Policy Research (CEPR), 2020.

Ghosh, J., "Messages from "Fiscal Space", 2020, en wwr.project-syndicate.org. , The Pandemic and the Global Economy, 2020, www.peri.umass. edu.

Marin, D., How COVID-19 Is Transforming Manufacturing, 2020, en www.project-syndicate.org.

Mitchell, W., The European Commission non-stimulus is a waiting game before new austerity is imposed, 2020, en http://bilbo.economicoutlook.net/blog/. 
, Bank of England official blows the cover on mainstream macroeconomics, 2020, en http://bilbo.economicoutlook.net/blog/. , Be careful not to get ahead of ourselves - hard-edged class struggle will be necessary, 2020, en http://bilbo.economicoutlook.net/blog/. , Eurozone inflation heading negative as the PEPP buys up bigdon't ask the mainstream to explain, 2020, en http://bilbo.economicoutlook.net/blog/. , The Bandwagon effect - caution not credit is needed, 2020, en http://bilbo.economicoutlook.net/blog/.

O’NeILL, J., Reading the COVID-19 Market, 2020, en www.project-syndicate.org.

Sheng, A. y Geng, X., Cooperate with China or Suffer, 2020, en wwre. project-syndicate.org. 
